\title{
Location-Based Reporting and Mapping of Crimes Using Google Maps
}

\author{
Jan B. Elnas, Eldrin C. Duran, James Leo E. Mayol, and Rabby Q. Lavilles
}

\begin{abstract}
Surveys showed that the majority of crimes committed were unreported to the authorities. Given this fact, this paper presents the development of a crime incidents reporting system with the use of Google Maps at the same time exploiting the active participation of netizens. This will provide another venue for reporting crime incidents. The idea draws its motivation from the inconvenience of going to the police station, personal belief of the weak investigative capabilities of the authorities to resolve petty crimes and limited dissemination of crime information to the community from the authorities. The system used Google Maps to present crime information accessible through a browser. In this way, people may report crimes using a location pointed on the map before providing detailed information. It enables an automatic method for displaying information on the map because the respondents itself identify the location. In addition, the system supports the idea of a witness hence; a crime can also be confirmed by other members of the community. This facility uses the idea of " +1 " or "like" method used by popular networking sites. The system is deployed for testing in the school but reporting can be done by the public. This scope allows the researcher to easily get the evaluation of the respondents. Currently, the system is deployed for testing and evaluation.
\end{abstract}

Index Terms - Crime reporting, Google map, mapping.

\section{INTRODUCTION}

With the advent of technology and its support for communications, people are also adopting the influence, fun and convenience that it offers. The service industry has changed its communication from text messages to email and even to use social networking. This phenomenon triggers businesses to provide value added services and improved communication lines to its customers or partners. Even the government is moving towards services offered online or easier way to access information to concerned citizens.

Law enforcement agencies in the Philippines especially in the cities might be using technology in their regular operation especially in the National Capital Regions or leading cities, but is limited in terms of reporting such as online reporting or crime information dissemination. Moreover, despite of this technological support, there is limited support on allowing people to communicate with them using the existing technology. The common method of reporting is to go to the police station and report an incident using a blotter. The police blotter is in a form of record book of reported crime

Manuscript received February 15, 2014; revised April 18, 2014. Thi work was supported in part by Information and Communications Technology Center of MSU-Iligan Institute of Technology.

The authors are with Information Technology, School of Computer Studies, MSU-Iligan Institute of Technology, Philipines (e-mail: rabby.lavilles@g.msuiit.edu.ph). incidents in a police station [1].

The Philippine Monthly Crime Report noted that the majority of crimes committed in Metro Manila go unreported [2]. This phenomenon is not only happening in the Philippines but also in other countries such as Canada [3]. Despite unreported crimes, it is common to encounter cases of uploaded videos or in social networking sites about crimes happening around [4], [5]. These cases showed the vigilance of the community of any incident they have encountered. In addition, people have gadgets or devices with them that usually captures the event.

In today's generation, active participation in electronic activities or social networking is prevalent. Almost every individual is using a social networking site as a way to update themselves or just to be part of the bandwagon. In addition some social networking sites support identification of their location automatically. Aside from social sites, there are other websites that cater the services such as news, current events and many more services providing the public with the latest information. In addition, people nowadays are very vigilant on any incidents occurring around them. Some even post it in video sharing websites or social networking sites. Despite of these available technologies, unreported cases of crimes are still popular and growing in numbers. This paper presents the development of a crime reporting system using Google Maps.

\section{Existing Process of Reporting Crimes in the Philippines}

Traditionally, police officers manually logs crime and complaints reported to them in a form of a police blotter. A police blotter is a logbook containing daily registry of all crime incident report, official summaries of arrest, and other significant events reported in police station [6].

The Philippine National Police (PNP) has launched its automated blotter system to solve the organizations' crime data backlog problems and make transmission of police records easier and faster. The e-Blotter system, which is designed to make recording of citizens' complaints faster and prevent police officers from tampering with records, is tested first in Metro Manila precincts [7].

With the new system, however, the reports would still be logged manually but at the same time, they will be encoded in a computer linked to the central server, which is accessible by all police stations nationwide. The software was developed by the PNP's DIDM, IT Management System and the Directorate for Information Computer Technology Management [7].

\section{RELATED STUDIES}

Numerous studies were conducted that allows citizens to 
report a crime online. One such study was by [8] of Florida, USA [9], wherein they used a website to encouraged the community to report crimes. The result revealed that $8.97 \%$ of the crimes reported are from online facility. Further evidence also shows that the public is willing to use the internet to report crimes online. In addition, they have computed a significant cost savings based on the study. The state developed an online crime reporting system for financial reasons. This is there alternative measures to save money in hiring additional people to work on reports in the office. The survey also includes an inquiry of the support of the community. The result clearly indicated that strong supports of $76.6 \%$ from the respondents were met. It also highlighted that $31.8 \%$ were victims of minor crimes who opt not to report because of inconvenience. An interesting number is 68.9 of the respondents would more likely to report a crime if the option to self-report from the convenience of one's home of office if available [10].

Aside from cities implementing online reporting of crimes, a study also looks on the spatial aspects of criminology and the relevance of place in understanding crime and criminality. They added that place local geography may be as significant as criminal motivation [11]. This showed that location is the integral part of crime investigation.

In North America, the company Omega Group developed crimemapping.com to help law enforcement agencies to provide the public with valuable information about recent crime activity in their neighborhood. The goal was to assist police departments in reducing crime through better informed citizens. This system allowed students and parents to received crime alerts for crime incidents occurring at or near the student dormitories or campus residence [12].

In Malaysia, particularly in Subang Java community, SJ Alert increases awareness of the people in the community about crimes happening. Started in 2006, a group of residents suggested the idea of a mass SMS dissemination of information about crime activities in the neighborhood [13].

Aside from crimes reporting online, there are studies that also apply the concept of participatory reporting in health. This study showed promising preliminary results on the use of mobile applications for information sharing and reporting that allowed the public to report infectious disease as it happens [14].

The short review of the literature showed an interesting interest of people in reporting crimes online through a website. In addition, mapping of incidents also matters to the public.

\section{METHODS}

The development of the system follows the following sequence. Start with requirements analysis, design, implementation and testing.

\section{A. Requirements Analysis and Scope}

The interview with the police officer assigned to record blotter allows the researcher to document the process of reporting. Sample reports and common crimes recorded were identified. The nature of the study and the limited time allowed limits the scope to five police stations in Iligan City,
Philippines, to be the source of data. The purpose of the study is to develop a system that will allow victims or individuals to report crime. It will not include the validation of crimes although the researcher will look for some verification of the crimes that might be identified for validity of the report.

To closely monitor and for ease of implementation, the testing stage will be announce in the campus. The target respondents are the students who are victims of petty crimes. This is to easily acquire the validation of crime respondents. The list of crimes that can be reported on the system are arson, assault, and bombing, burglary, disturbing the peace, alcohol violations, fraud, homicide, vehicle theft, robbery, sex crimes, and theft. An equivalent Filipino translation is also integrated in the system for respondents to understand the crime.

\section{B. Design and Implementation}

During the design, a Unified Modeling Language was used to analyze and define the functionalities and behavior of the system. Specifically, Use Cases were used to define the functionalities while Sequence diagram was used to primarily show the interactions between objects and the order of connections and communication [15]. An entity relationship diagram was also derived and created to support the data requirement as shown in Fig. 1.

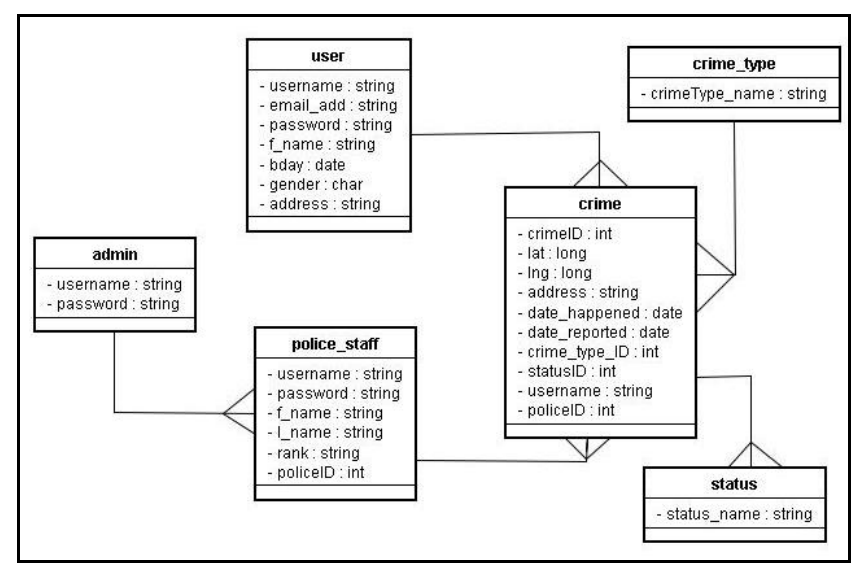

Fig. 1. Entity relationship diagram.

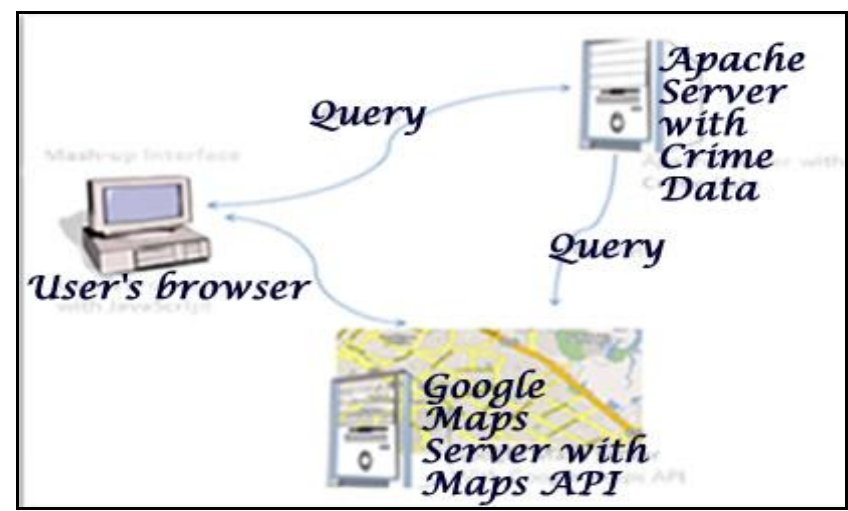

Fig. 2. Interaction of major components of the system.

The interface design was implemented using Google Maps where crimes can be viewed based on location using an icon which also indicates the type of crime. Since Google Maps Application Programming Interface (API) were available for developers to use, a mash-up with crime reports from the users enable the user to report crimes which also serves as a web service that can be use to disseminate crime information. Once a crime has been reported by a respondent, this will be 
viewed by other users which will allow them confirm if they have witnessed it. The number of confirmation will be ranked by the system for the police officers view possible unreported crime incidents.

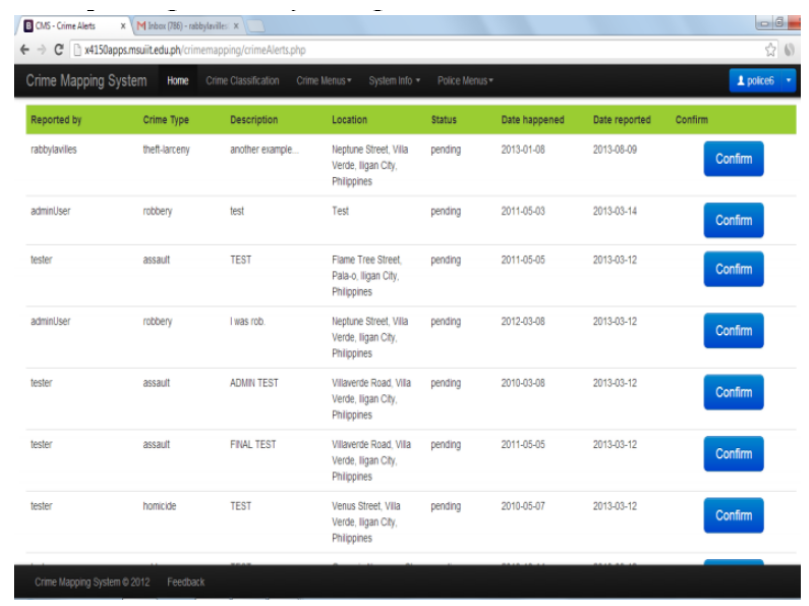

Fig. 3. Crime reports received by police office.

The entity-relationship diagram was implemented using a mysql as database management software for information reported. The database is then accessed through a php script that generates an eXtensibleMarkup Language (XML) file. A javascript code is then used to produce a data ready for display using jsChart [16]. This chart is used to visualize the number of crime occurrences. The user interface was designed using Twitter boostrap and jQuery [17]. This is to adopt the design used by popular website for familiarity of the design.

\section{Testing and Deployment}

Fig. 2 shows the interactions of the components required to create and run the application. The first request is initialized at the browser, where the user would report a crime by putting a marker in the location on the map where the crime happened. By the used of Ajax the location of the marker is sent to the Apache Server. PHP then creates a formatted $\mathrm{XML}$ with the data from the database which is received by Ajax and parsed with JavaScript. When the JavaScript has the information, it can then call the Google API to load the map specific to that location. The process is then repeated, using a different PHP and AJAX script to load the map.

Alpha and beta testing were conducted to verify and evaluate the functionalities of the system. Alpha testing was guided through the Use Cases developed during the first and second phase of the development. After alpha testing, the system was deployed in a university server for testing. In beta testing, the uploaded system was accessed by the user through a given website. Two major users were supported: reporting and affirming the crime, and police officers view where the police can confirm and view crime reports.

\section{RESULTS AND DISCUSSIONS}

This section presents the result of the development and testing of the system. Two interfaces were included, the police and the respondents who reported the crime or incident For initial security it also requires the basic features such as identification through signup including login and logout.

\section{A. Reporting and Confirming Crimes}

Respondents can report a crime, view a crime graph, confirm a crime, upload an image or video and view the crime in the application. When reporting a crime, the user point to a location in the map where the crime occur. The system will retrieve the latitude and longitude based on the Google API and save it to the local database where the application is directly connected. This will be used to show the crime in the map.

A user can confirm a crime in cases where he/she is witness. This is done by clicking the icon in the map representing the crime reported and a popup menu will display. A user can then click the confirm button which will add to the number of counts confirming the crime. A user has an option also to upload a picture or provide a link from Youtube where the video was captured.

\section{B. Validation of Reports}

Once the user confirmed a crime, it will add to the count which provides the basis for validation. In this test, a crime reported by a respondents need to be confirmed by at least 7 (seven) witnesses or user of the system to be considered a true reported crime which can be viewed by the public. The 7 (seven) confirmations as a requirement before it will be displayed in public was based on the implementation of SJ Alert [13].

Moreover, authorities are allowed also to confirm a crime. Whenever a police confirmed a crime, the system will automatically consider it as validated report. Furthermore, a crime is automatically validated once the police user reported it.

\section{Testing}

The testing was conducted by Information Technology students using the Use Cases specified by the developers. Fig. 3 shows a sample interface which provides an overview of the Iligan City in Google map with the crimes based on the location.

Beta testing was done to evaluate the system based on the perception of the users for the last two months of its deployment. The result showed that in terms of ease of used, $86 \%$ agreed that it is easy to use, even without a manual.

In response to the hesitation of people to report crimes online, after using the system, we ask the tester participants if they will return to the site to report or affirm a crime or incident. The result showed that $72 \%$ is open to return to the site to report an incident. Those who disagree explained that the report on this site might not be reliable.

We ask also the perception of users in terms of the usefulness of the system. An interesting feedback of $96 \%$ told us that it is useful and that $90 \%$ is willing to volunteer to confirm or verify a crime when they can witness it. Though the result varied, $100 \%$ of the respondents would recommend the system to be implemented in partnership with the authorities.

On the side of the police, an average of $80 \%$ agrees that it is easy to use and that it will not require a manual to navigate. The same number of police evaluator's agreed that it would enable them to accomplish task easily such as recording a report or mapping an incident. When asked about their willingness to allow us to install the system in their office, 
$100 \%$ agreed. Fig. 4 showed an interface for the reported crimes. It was arranged according to the number of confirmation the crime has. The sequence is in ascending order so that the police can easily see crimes with greater number of confirmations. Several issues have been raised during the evaluation both from the police and students respondents. One of these is the street names generated by
Google Maps. In cases where the street name is not yet registered or not labeled by Google Maps, it uses the nearest street name which does not necessarily be the name of the street identified by the user. There are also instances that the same crime might be reported twice because the feature of identifying the same crimes reported by the user was not considered during the development.

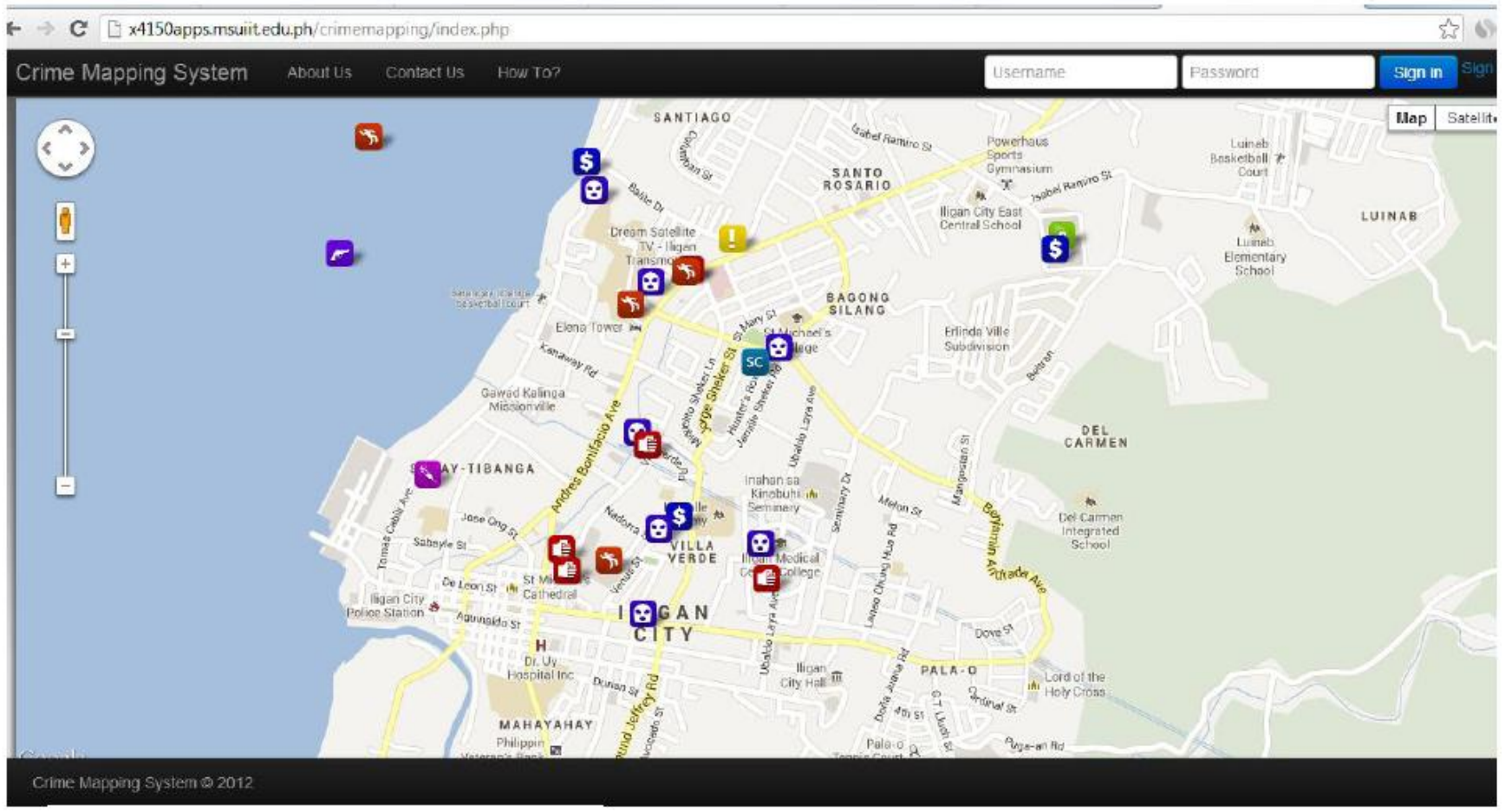

Fig. 4. Sample interface showing crimes reported.

\section{CONCLUSION}

The system prototype allows users to report a crime or incident paving the way for residents to report or verify incidents by providing the location of the incidents encountered or witnessed. Since exact location or coordinates are already identified by respondents, the data can be automatically displayed in the map without giving burdens to the police to encode it again. In addition, the actual location of the incidents can also be identified which gives an idea to the community about the location where common crimes happened.

The result of the test showed that the potential users are willing to participate and already recognized the usefulness of the system. The willingness of the police to use the system and their recognition of its usefulness is enough to try the system for community use.

\section{RECOMMENDATIONS}

Based on the findings of the study, the researchers recommend the following for further study: widening the limit of the system by considering other cities; upgrade the system by detecting double reported crimes or incidents and examine the success of citizens self reporting crimes online from the perspective of the law enforcement agencies receiving the online reports.

Examining the validity of reports using the crowd is worth an attention. This is a good source of information but validation is a challenge that needs to be studied.

\section{REFERENCES}

[1] A. G. Caro, Philippine National Police Manual, 2010.

[2] Philippine Monthly Crime Report 2011. (May 12, 2013). Philippine MOnthly Crime Report. [Online]. Available: http://www.psagroup.com/knowledgesalescenter/index.php/philippines-monthly-crime-report- december-2011-2/

[3] CBC News. (2010). More crimes going unreported: survey. [Online]. Available:

http://www.cbc.ca/news/canada/story/2010/09/28/statscan-victimizati on-survey.html.

[4] S. Ali, "Crime and Mobile phones," Yuppee Mag., June 30, 2013.

[5] C. Diola, PNP probes 'brutality' in viral video, Manila: Philippine Star, 2013.

[6] Philippine National Police Manual Operational Procedures. (2010). Philippine National Police. [Online]. Available: http://www.dipovis.pnp.gov.ph/download/pnppopmanual2010.pdf.

[7] P. Rufino. (October 10, 2011). Philippine Police Deploys Automated Record System. Future Gov Asia. [Online]. Available: http://www.futuregov.asia/articles/2011/oct/10/philippine-police-depl oys-automated-records-system.

[8] V. de Water et al.. (January 12, 2013). Citizens Self Reporting Crimes Online: The Law Enforcement perspective. [Online]. Available: http://www.fdle.state.fl.us/Content/getdoc/7f75953c-7c044f46-9ac1-9d63079343fe/Vandewater-final-paper-pdf.asp.

[9] L. Langton, M. Berzofsky, C. Krebs, and H. Smiley-McDonald (August 2012). Bureau of Justice Statistics. [Online]. Available: http://www.bjs.gov/content/pub/pdf/vnrp0610.pdf.

[10] D. Farber. (January 5, 2013). [Online]. Available: http://www.fdle.state.fl.us/Content/getdoc/ffe4a656-127a-4d32-a7572049d5492cd6/Farber-darin-final-paper-(1).aspx.

[11] J. Ratcliffe, Handbook of Quantitative Criminology, pp. 5-21, Springer Science Business Media, 2010. 
[12] Crimemapping.com. (February 23, 2013). [Online]. Available: http://www.crimemapping.com/.

[13] SJAlert. (January 23, 2013). [Online]. Available: http://www.sjalert.com.my/.

[14] C. C. Freifeld, R. Chunara, S. R. Mekaru et al., "Participatory Epidemiology: Use of Mobile Phones for Community-Based Health Reporting," PLoS Med., vol. 7, no. 12, p. e1000376, doi:10.1371/journal.pmed.1000376, 2010

[15] D. Bell. (February 16, 2004). IBM Developers Work. [Online]. Available:

http://www.ibm.com/developerworks/rational/library/3101.html.

[16] J. S. Charts. (May 12, 2013). [Online]. Available: http://www.jscharts.com/.

[17] J. Query. (April 12, 2013). What is JQuery? [Online]. Available: http://jquery.com/.

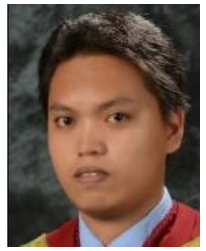

Jan B. Elnas was a graduate of bachelor of science in information technology at the School of Computer Studies of Mindanao State University - Iligan Institute of Technology.

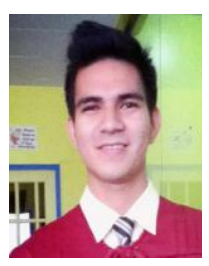

Eldrin C. Duran was a graduate of bachelor of science in information technology at the School of Computer Studies of Mindanao State University - Iligan Institute of Technology.

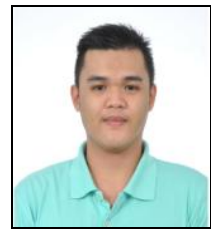

James Leo E. Mayol was a graduate of bachelor of science in information technology at the School of Computer Studies of Mindanao State University Iligan Institute of Technology.

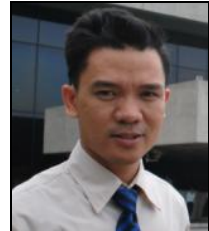

Rabby Q. Lavilles is an assistant professor of the information technology, School of Computer Studies, Mindanao State University - Iligan Institute of Technology. He was a graduate of master of science in information technology at De La Salle University-Manila, Philippines. 